\title{
Endovascular treatment of aortoiliac occlusive disease involving the aortic bifurcation: Case Report
}

\author{
Funda Yıldırım¹, Dilşad Amanvermez Şenarslan'1, Adnan Taner Kurdal ${ }^{1}$, Tülün Öztürk¹, \\ Abdülkerim Damar ${ }^{1}$, Mustafa Cerrahoğlu ${ }^{1}$, İhsan İşkesen ${ }^{1}$, Ömer Tetik ${ }^{1}$
}

1) Celal Bayar University, Hafsa Sultan Hospital, Department of Cardiovascular Surgery, MD, Manisa, Turkey

\begin{abstract}
Endovascular treatment of aortoiliac occlusive disease (AIOD) involving the aortic bifurcation is challenging. We presented you a 81 year-old male patient suffering from vertigo and buttock claudication. Both carotid and peripheric angiographies were performed in our cardiovascular clinic. The left carotid artery was $90 \%$ stenotic and the distal abdominal aorta was occluded (TASC II Classification, Type C lesion, short segment distal aortic occlusion at aortic bifurcation). The patient underwent endovascular treatment for AIOD (occlusive lesion at aortic bifurcation), two weeks after the carotid endarterectomy operation. The occlusions were recanalised succesfully with a bare-metal self expandable stent and two kissing covered ballon expandable stents for both iliac arteries. Endovascular treatment of aortic bifurcation lesions is a suitable, less invasive alternative for high-risk patients for open surgery.
\end{abstract}

Key words: Aortoiliac occlusive, aortic bifurcation, endovascular treatment, distal abdominal aorta.

Yıldırım F., Amanvermez Şenarslan D., Kurdal A. T., Öztürk T., Damar A., Cerrahoğlu M., İşkesen İ., Tetik Ö. Endovascular treatment of aortoiliac occlusive disease involving the aortic bifurcation: Case Report EJCM 2018; 06 (1): 23-26. Doi: 10.15511/ejcm.18.00123. 


\section{Introduction}

Endovascular treatment of aortoiliac occlusive disease (AIOD) involving the aortic bifurcation is challenging. The firstline therapy is open surgery with patency rates up to $90 \%$ at 5 years but it has considerable morbidity and mortality. Endovascular treatment of aortic bifurcation lesions is a suitable, less invasive alternative for high-risk patients for open surgery.

\section{Case}

We presented you a 81 year-old male patient suffering from vertigo and buttock claudication. The computed tomography anjiography showed peripheral arterial occlusive disease that generates nearly occlusion at bilateral main iliac arteries (Figure 1). He was admitted to our cardiovascular surgery department and we performed peripheral and carotid anjiography; the patient had TASC II classification, Type C lesion, short segment distal aortic occlusion at the entrance to the main iliac arteries and 90\% narrowing at left carotid artery (Figure 2,3).

Primarily left carotid endarterectomy operation was performed without any problem. The patient underwent endovascular treatment for distal abdominal aorta occlusion (occlusive lesion at aortic bifurcation), two weeks after the carotid endarterectomy operation. A bare-metal self expandable stent (WallstentTM) and

Figure 1. Computed tomography (CT) anjiographic view of nearly occlusion in bilateral main iliac arteries at level of aortic bifurcation.

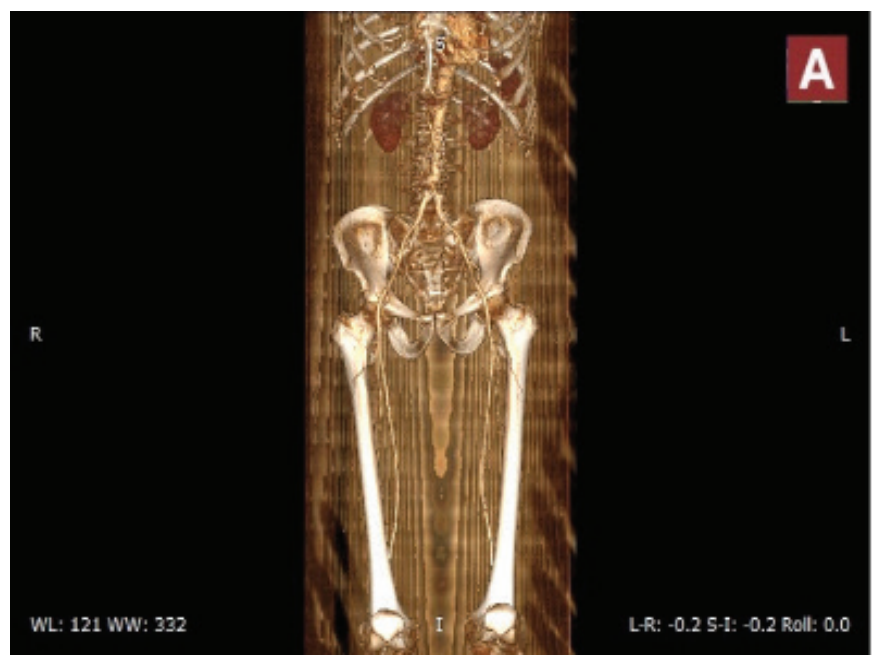

two kissing covered ballon expandable stents (Atrium, Advanta V12TM) for both iliac arteries were implanted in our hybrid operating room. The occlusions were recanalised succesfully (Figure 4). The distal pulses were palpable and no complications were observed related to the intervention. The patient was discharged 3 days later after the intervention.

\section{Discussion}

Chronic occlusion of the distal abdominal aorta and bilateral iliac arteries is termed infrarenal aortoiliac occlusion and categorized by the Trans-Atlantic InterSociety Consensus for the Management of Peripheral Arterial Disease (TASC II) as a type C or variant of a type D lesion. TASC II guidelines recommends surgical therapy for type $\mathrm{C}$ and $\mathrm{D}$ lesions whereas endovascular treatment remains in the forefront. ${ }^{(1)}$

Aortabifemoral bypass is regarded as the gold standard for the treatment of severe AIOD with 5 and 10 years patency rates approximately $90 \%$ and $75 \%$ respectively. But with the improvements in endovascular techniques and balloon, stent technology, more successful endovascular interventions were accomplished for the treatment of complex aortoiliac lesions. But the long term patency rates of endovascular therapies are uncertain for type C and D lesions. ${ }^{(2-4)}$ In some recent reports authors revealed good results that approximating those of open surgery for type B or C lesions. ${ }^{(5-8)}$

Figure 2. Anjiographic view of $90 \%$ narrowing at left carotid artery.

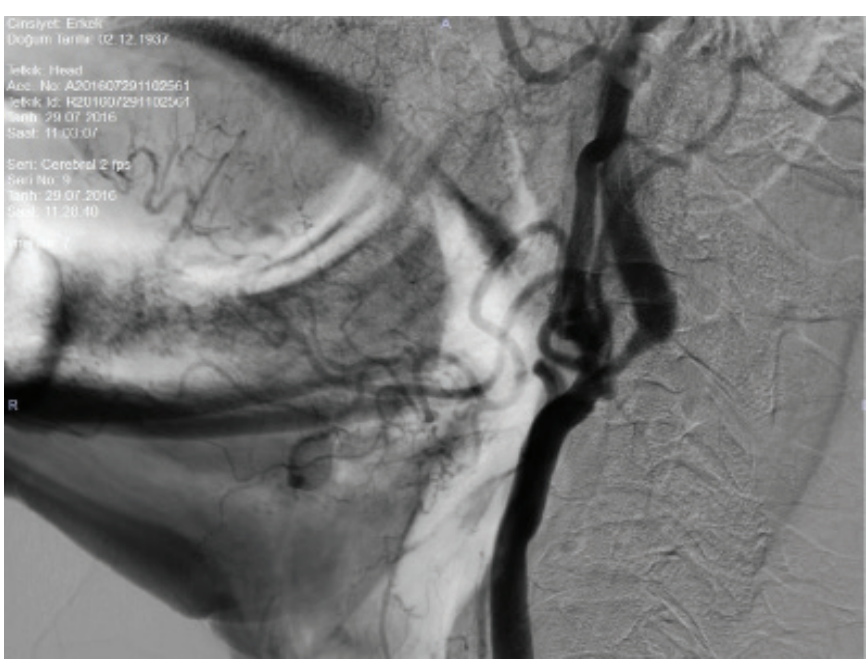


Saher S Sabri at al. reported fifty-four patients with atherosclerotic occlusive disease at the aortic bifurcation that treated by kissing stents. They compared the results of bare metal ballon expandable stents with covered stents. Technical success was achieved in $100 \%$ of patients in both groups. They declared better patency rates in covered stent group than bare metal stents at median 21 months follow up. Improvement of symptoms was also better in covered stent group. ${ }^{(9)}$

In this case we used a bare metal self-expandable stent (Wallstent Endoprosthesis TM )at the level of infrarenal aorta, to benefit its high radial force. Then we used two kissing covered balloon expandable stents (Atrium, Advanta V12TM, Maquet, Getinge Group) that entering into the Wallstent endoprosthesis at the proximal part, for eliminating the occlusion of the aortic bifurcation.

Lun $\mathrm{Y}$ et al. compared midterm outcomes of aortoiliac stent (AIS) placement with those of surgical treatment in patients with chronic infrarenal aortoiliac occlusion. The technical success rate was significant-

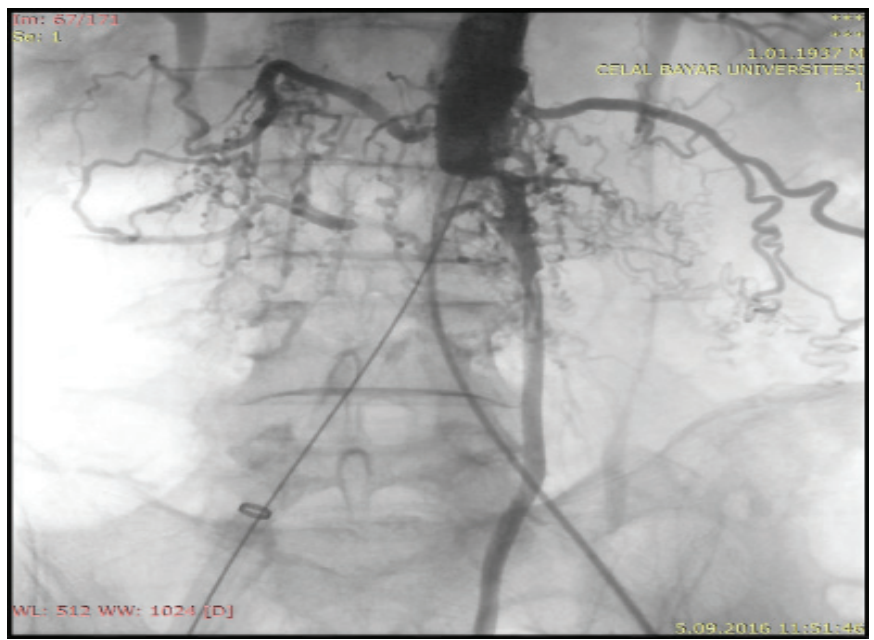

Figure 3. Anjiographic view of peripheral occlusive disease at distal abdominal aorta (TASC II classification, Type C lesion) ly lower in the AIS group than in the surgery group. Surgically treated patients had a longer average postoperative hospital stay and higher rates of postoperative complications caused by especially respiratory and renal disfunction and multiple organ failure. AIS for infrarenal abdominal aortic occlusions were associated with a shorter hospital stay and lower postoperative morbidity rates than open surgery. ${ }^{(2)}$

Endovascular treatment of extensive AIOD can be performed successfully by experienced interventionists in selected patients. This case was an example of serious, nearly total occlusion of distal aorta just at the aortic bifurcation. The occlusion is treated succesfully with endovascular therapy.

Endovascular procedures enables us to avoid abdominal incision, related postoperative serious complications and prolonged hospital stay. Endovascular therapies for type C and D lesions with good outflow, appears to be a safe, feasible and minimally invasive method with lower morbidity than open surgery especially in high-risk patients.

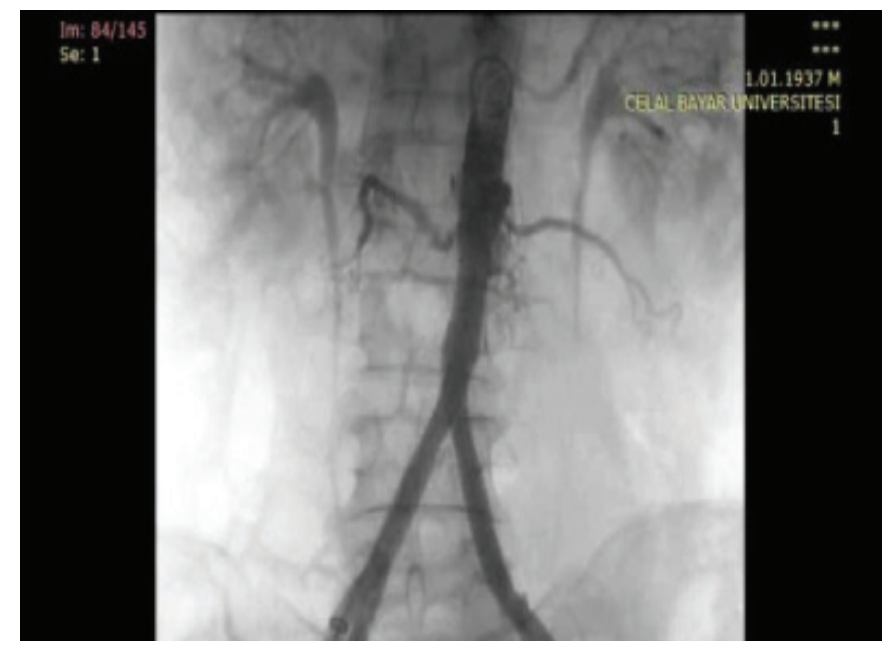

Figure 4. Succesfully treated distal abdominal aortic peripheral arterial occlusive disease (near occlusion at level of aortic bifurcation) by a bare-metal self expandable stent (WallstentTM) and two kissing covered ballon expandable stents (Atrium, Advanta V12TM). 


\section{References}

1. Norgren L, Hiatt WR, Dormandy JA, Nehler MR, Harris KA, Fowkes FG et al. Inter-Society Consensus for the Management of Peripheral Arterial Disease (TASC II). Eur J Vasc Endovasc Surg 2007; 33 (1): 1-75.

2. Lun Y, Zhang J, Wu X, Gang Q, Shen S, Jiang H et al. Comparison of midterm outcomes between surgical treatment and endovascular reconstruction for chronic infrarenal aortoiliac occlusion. J Vasc Interv Radiol 2015; 26(2): 196-204.

3. Groot Jebbink E, Holewijn S, Slump CH, Lardenoije JW, Reijnen MMPJ. Systematic Review of Results of Kissing Stents in the Treatment of Aortoiliac Occlusive Disease. Ann Vasc Surg 2017; 42: 328-36.

4. Grimme FA, Goverde PC, Verbruggen PJ, Zeebregts CJ, Reijnen MM. First Results of the Covered Endovascular Reconstruction of the Aortic Bifurcation (CERAB) Technique for Aortoiliac Occlusive Disease. Eur J Vasc Endovasc Surg. 2015; 50(5): 638-47.

5. Hans SS, DeSantis D, Siddiqui R, Khoury M. Results of endovascular therapy and aortobifemoral grafting for Transatlantic Inter-Society type
C and D aortoiliac occlusive disease. Surgery 2008; 144(4): 583-9; discussion 589-90.

6. Sachwani GR, Hans SS, Khoury MD, King TF, Mitsuya M, Rizk YS et al. Results of iliac stenting and aortofemoral grafting for iliac artery occlusions. J Vasc Surg. 2013; 57(4): 1030-7.

7. Jongkind V, Akkersdijk GJ, Yeung KK, Wisselink W. A systematic review of endovascular treatment of extensive aortoiliac occlusive disease. J Vasc Surg 2010; 52(5): 1376-83.

8. Kashyap VS, Pavkov ML, Bena JF, Sarac TP, O’Hara PJ, Lyden SP et al. The management of severe aortoiliac occlusive disease: endovascular therapy rivals open reconstruction. J Vasc Surg 2008; 48(6): 1451-7.

9. Sabri SS, Choudhri A, Orgera G, Arslan B, Turba UC, Harthun NL et al. Outcomes of covered kissing stent placement compared with bare metal stent placement in the treatment of atherosclerotic occlusive disease at the aortic bifurcation. J Vasc Interv Radiol 2010; 21(7): 9951003.

Received: 16/06/2017

Accepted: 18/01/2018

Published: 15/03/2018

Disclosure and conflicts of interest:

The authors declare no conflict of interest.

\section{Corresponding author:}

Dr. Funda Yıldırım

Mail: fundanizamoglu@yahoo.com 